\title{
Normalized evaluation of thermal shock resistance for ceramic materials
}

\author{
Kai LI ${ }^{a, b}$, Dalei $\mathrm{WANG}^{a}$, Han $\mathrm{CHEN}^{a}$, Lucun GUO ${ }^{a,}$ \\ ${ }^{a}$ College of Materials Science and Engineering, Nanjing University of Technology, Nanjing 210009, China \\ ${ }^{b}$ Institute of Metal Research, Chinese Academy of Sciences, Shenyang 110016, China
}

Received: April 21, 2014; Revised: July 19, 2014; Accepted: July 22, 2014

CThe Author(s) 2014. This article is published with open access at Springerlink.com

\begin{abstract}
A normalized method for evaluation of thermal shock resistance for ceramic materials was proposed. A thermal shock resistance index (TSRI), $\Gamma$, in the range of 1 to 100 , was introduced, based on a normalized formula obtained directly by a simple testing process of determining the changes in flexural strength before and after thermal shock cycles. Alumina ceramic was chosen as the model material and its thermal shock behavior was investigated systematically by water quenching. Based on the experiments on alumina ceramic, the thermal shock behaviors of other 19 types of ceramic materials ranging from porcelain, refractory ceramics to advanced ceramics including structural and functional ceramics were also evaluated, and their TSRIs, $\Gamma$, were derived. The dependence of $\Gamma$ on the coefficient of thermal expansion (CTE) of the materials was plotted, and it revealed that CTE is the most critical factor in affecting the thermal shock resistance for various ceramic materials. The effect of other factors such as porosity and fracture toughness on the index was also discussed.
\end{abstract}

Keywords: thermal shock resistance; evaluation; ceramic materials; flexural strength

\section{Introduction}

Ceramic materials are widely used in various fields of engineering because of their many excellent properties such as high hardness, high melting points, resistance against oxidation and chemical corrosion, and high-temperature stability [1-3]. The susceptibility of ceramic materials to thermal shock is one of the main factors limiting their applications [4,5]. The thermal shock resistance provides a measure of the ability of ceramic materials to withstand thermal stresses and thermal shock failure when they are subjected to rapid changes in temperature $[4,6]$. For those that are applied under transient thermal environments, for instance, high-temperature furnaces, filtration for hot gases or molten metal, heat exchangers, gas turbine engines, solid oxide fuel cell and catalyst supports [7-11], the

* Corresponding author.

E-mail: 1c-guo@163.com thermal shock resistance of materials is a crucial factor determining the durability. Therefore, understanding and assessing the thermal shock and fatigue behavior of ceramics are of great importance for the application with high reliability at elevated temperature $[3,12]$. In contrast to metals, which yield and deform plastically before failure, a major characteristic of ceramics is that they are brittle and fracture with little or no deformation [4]. The high degree of brittleness and unfavorable combination of such properties as low thermal conductivity and high Young's modulus can render high susceptibility of ceramic materials to catastrophic failure under thermal shock conditions with high magnitude of thermal stress $[13,14]$.

In the past several decades, many strides aiming at the development of theories and methods for evaluating thermal shock resistance of ceramics have been reported [15-19]. However, the approaches currently used in the evaluation of thermal shock resistance are largely based on the research results of 
Kingery [15] and Hasselman [16]. On the basis of the thermoelastic theories, the first theory of thermal shock resistance focusing attention on the initiation of fracture resulted from thermal stresses was presented by Kingery, who defined a parameter $R^{\prime}$ for evaluating of the thermal shock resistance. This parameter was represented as [15]:

$$
R^{\prime}=\frac{\sigma_{\mathrm{f}}(1-v) k}{E \alpha}
$$

where $\sigma_{\mathrm{f}}$ is the flexural strength; $E$ is the Young's modulus; $\alpha$ is the linear expansion coefficient; $v$ is the Poisson's ratio; and $k$ is the thermal conductivity.

The second approach proposed by Hasselman concentrated mainly on the extent of crack propagation whereas ignored the issue of fracture initiation in thermal environments. The evaluation parameter $R^{\prime \prime}$ derived by Hasselman was given in the following equation [16]:

$$
R^{\prime \prime}=\frac{E}{\sigma_{\mathrm{f}}^{2}(1-v)}
$$

Both theories indicate that the factors affecting thermal shock resistance of ceramic materials are a complex function of the coefficient of thermal expansion, flexural strength, elastic properties and thermal conductivity. Obviously, the demands for modulus and strength in the second parameter stand in direct opposition to those in the first parameter. In fact, the reason why the two theories are contradictory is that their rationales and the criteria are different [4]. Hence, they may not be the proper criteria for accurately analyzing and forecasting the thermal shock resistance of ceramic materials under the transient thermal conditions. Hasselman tried to unify the two theories, and then presented a unified theory of thermal shock fracture initiation and crack propagation [17]. However, this approach appeared to not agree well with certain observations of ceramics $[10,12,20]$. Although the theoretical knowledge plays a significant role in understanding of the underlying mechanisms for thermal shock behavior of ceramics, it fails to lead to a unified test standard for evaluating and comparing the thermal shock resistance of ceramics.

Evaluation of thermal shock resistance showing thermal endurance can be extremely challenging due to complex factors influencing it $[5,21]$. Over the past several decades, various methods for the determination of thermal shock resistance have been proposed or employed by a great many researchers [19-25]. Almost all of these methods applied to measure the thermal shock resistance of ceramic materials are often seen to consist of three steps: first, the samples are plunged into a cooling medium such as water, oil or air from an elevated temperature; then, the changes of material properties with different temperature differences after thermal shock treatment, frequently just for a single cycle, such as the loss of weight [15] and the decrease in strength or elastic modulus [13,19], have been traditionally employed to assess the thermal shock resistance of materials; finally, based on the data obtained from above steps, a designed factor intending to reflect the thermal shock resistance of ceramics is attained. Among a number of evaluation methods, a general indicator used to evaluate thermal shock resistance is the critical temperature difference, $\Delta T$, determined at which there is a sudden decrease in flexural strength or elastic modulus [22], or at which the large crack causing the failure of a material is produced with an indentation-quench method [23]. It is widely believed that the higher the value of $\Delta T$, the better the thermal shock resistance. Unfortunately, these evaluation parameters for thermal shock resistance may not be readily obtained, because the determination of the desired critical temperature interval depends largely on a complicated experimental procedure. In ASTM Standard C1525-04, a critical temperature interval is determined by a $30 \%$ reduction in flexural strength after single thermal shock compared with the mean flexural strength of the as-received specimens [26]. Nevertheless, this indicator in the $30 \%$ reduction of the original mean strength is difficult to be accurately obtained. An evaluation parameter in the European Standard is the critical temperature difference determined at which fracture is just initiated, or at which there is a first drop in mean strength by more than $30 \%$ of the initial mean strength [27]. Thus, these evaluating methods not only are time-consuming, but also have limited ability to clearly distinguish among different levels of thermal shock resistance for a wide range of ceramic materials with a manner of quantification. Although the testing methods of non-destructive characterization are performed to determine elastic changes in refractory materials subjected to thermal shock cycles, for example, ultrasonic velocity measurement and forced resonance technique [24,25], their feasibility and validation for quantitatively assessing various ceramics have not been reported.

Until now, a unified parameter or index accepted by both academia and industry has not been established 
for various ceramic materials, although many attempts to evaluate thermal shock resistance of ceramics have been made. Therefore, from the point of view of practice purpose, a simple and unified evaluation method for determining the thermal shock resistance of ceramic materials will be much expected. Here, we report a normalized method based on the introducing index for evaluation of thermal shock resistance of various ceramic materials.

\section{Experimental procedures}

\section{1 Material selection and specimen preparation}

The materials used in the current experiments are all commercially available ceramics which are widely applied in industries. The main chemical compositions of experimental powders used for the preparation of each ceramic, which were determined using X-ray fluorescence spectrometry, are summarized in Table1. Green bodies of $99^{\#}$ alumina ceramic were fabricated from commercial $\alpha-\mathrm{Al}_{2} \mathrm{O}_{3}$ powders $(1.36 \mu \mathrm{m}, 99 \%$ pure, Jiyuan Jinghua Material Co., Henan, China) by uniaxial pressing at the pressure of $50 \mathrm{MPa}$ in a rectangular stainless steel die. The bars of alumina ceramic were sintered without pressure at $1600{ }^{\circ} \mathrm{C}$ for $2 \mathrm{~h}$ in a $\mathrm{MoSi}_{2}$ resistance-heated box furnace. In addition, a cold isostatic pressing at the pressure of $\sim 300 \mathrm{MPa}$ was applied to several materials including
$\mathrm{AlN}, \mathrm{SiC}$ and fused quartz ceramic $\left(\mathrm{SiO}_{2}\right)$. All the specimens were made using the same method of pressureless sintering process. To avoid the influence of specimen size and geometry, all the testing specimens were rectangular bars with dimensions of $3 \mathrm{~mm} \times 4 \mathrm{~mm} \times 50 \mathrm{~mm}$. The four surfaces of each specimen were ground and then polished using a glazing machine. All the specimens were chamfered on each edge, and polished aiming to reduce stress concentration. The specimens were divided with four in a group, and used for the thermal shock test under each condition. The density and open porosity of the sintered specimens were measured by the water absorption method according to Archimedes' principle. The coefficient of thermal expansion (CTE) of these ceramics up to $800{ }^{\circ} \mathrm{C}$ was measured by a dilatometer (Model 402C, Netzsch GmbH, Selb, Germany) in air or in flowing $\mathrm{N}_{2}$ at a heating rate of $5{ }^{\circ} \mathrm{C} / \mathrm{min}$.

\section{2 Thermal shock experiments}

Thermal shock test was performed in an automatic device made up of a vertical tube furnace for heating the specimens, a K-type thermocouple, an electromotor served as the succession of thermal shock cycles, and a tank of fluid water for quenching. A set of the test specimens was heated to a desired temperature in the preheated furnace, held for $2 \mathrm{~min}$ and then automatically transferred at a given rate into a bath of water controlled at room temperature. The specimens

Table 1 Main chemical compositions of experimental powders

\begin{tabular}{|c|c|c|c|c|c|c|c|c|c|}
\hline Material & \multicolumn{4}{|c|}{ Major chemical constituent (wt\%) } & Material & \multicolumn{4}{|c|}{ Major chemical constituent (wt\%) } \\
\hline \multirow{2}{*}{$\mathrm{KZr}_{2}\left(\mathrm{PO}_{4}\right)_{3}$} & $\mathrm{P}_{2} \mathrm{O}_{5}$ & $\mathrm{ZrO}_{2}$ & $\mathrm{~K}_{2} \mathrm{O}$ & $\mathrm{ZnO}$ & \multirow{2}{*}{$3 \mathrm{Al}_{2} \mathrm{O}_{3} \cdot 2 \mathrm{SiO}_{2}$} & $\mathrm{Al}_{2} \mathrm{O}_{3}$ & $\mathrm{SiO}_{2}$ & $\mathrm{Y}_{2} \mathrm{O}_{3}$ & $\mathrm{MgO}$ \\
\hline & 44.69 & 43.55 & 7.46 & 2.56 & & 75.17 & 22.25 & 1.20 & 0.36 \\
\hline \multirow{2}{*}{ Fused $\mathrm{SiO}_{2}$} & $\mathrm{SiO}_{2}$ & $\mathrm{Al}_{2} \mathrm{O}_{3}$ & $\mathrm{CaO}$ & $\mathrm{MgO}$ & \multirow{2}{*}{$99^{\#} \mathrm{Al}_{2} \mathrm{O}_{3}$} & $\mathrm{Al}_{2} \mathrm{O}_{3}$ & $\mathrm{Y}_{2} \mathrm{O}_{3}$ & $\mathrm{La}_{2} \mathrm{O}_{3}$ & $\mathrm{MgO}$ \\
\hline & 99.72 & 0.25 & 0.01 & 0.01 & & 98.43 & 0.67 & 0.25 & 0.22 \\
\hline \multirow{2}{*}{$\mathrm{Si}_{3} \mathrm{~N}_{4}$} & $\mathrm{Si}_{3} \mathrm{~N}_{4}$ & $\mathrm{Y}_{2} \mathrm{O}_{3}$ & $\mathrm{Al}_{2} \mathrm{O}_{3}$ & $\mathrm{Fe}_{2} \mathrm{O}_{3}$ & \multirow{2}{*}{$\mathrm{MgO}$} & $\mathrm{MgO}$ & $\mathrm{Al}_{2} \mathrm{O}_{3}$ & $\mathrm{SO}_{3}$ & $\mathrm{Cl}^{-}$ \\
\hline & 86.55 & 8.25 & 3.83 & 0.47 & & 86.48 & 10.75 & 2.36 & 0.25 \\
\hline \multirow{2}{*}{ Petalite ceramic } & $\mathrm{SiO}_{2}$ & $\mathrm{Al}_{2} \mathrm{O}_{3}$ & $\mathrm{Fe}_{2} \mathrm{O}_{3}$ & $\mathrm{~K}_{2} \mathrm{O}$ & \multirow{2}{*}{ Porcelain } & $\mathrm{SiO}_{2}$ & $\mathrm{Al}_{2} \mathrm{O}_{3}$ & $\mathrm{~K}_{2} \mathrm{O}$ & $\mathrm{CaO}$ \\
\hline & 64.41 & 31.91 & 0.79 & 0.74 & & 67.66 & 27.09 & 2.60 & 0.87 \\
\hline \multirow{2}{*}{ Spodumene ceramic } & $\mathrm{SiO}_{2}$ & $\mathrm{Al}_{2} \mathrm{O}_{3}$ & $\mathrm{Li}_{2} \mathrm{O}$ & $\mathrm{Fe}_{2} \mathrm{O}_{3}$ & \multirow{2}{*}{$3 \mathrm{YSZ}$} & $\mathrm{ZrO}_{2}$ & $\mathrm{Y}_{2} \mathrm{O}_{3}$ & $\mathrm{HfO}_{2}$ & $\mathrm{Cl}^{-}$ \\
\hline & 56.33 & 29.40 & 11.77 & 0.66 & & 92.08 & 5.53 & 1.58 & 0.49 \\
\hline \multirow{2}{*}{$2 \mathrm{MgO} \cdot 2 \mathrm{Al}_{2} \mathrm{O}_{3} \cdot 5 \mathrm{SiO}_{2}$} & $\mathrm{SiO}_{2}$ & $\mathrm{Al}_{2} \mathrm{O}_{3}$ & $\mathrm{MgO}$ & $\mathrm{SO}_{3}$ & \multirow{2}{*}{ 8YSZ } & $\mathrm{ZrO}_{2}$ & $\mathrm{Y}_{2} \mathrm{O}_{3}$ & $\mathrm{HfO}_{2}$ & $\mathrm{Al}_{2} \mathrm{O}_{3}$ \\
\hline & 49.79 & 32.40 & 13.47 & 2.28 & & 83.25 & 14.66 & 1.42 & 0.24 \\
\hline \multirow{2}{*}{$\mathrm{CaZr}_{2}\left(\mathrm{PO}_{4}\right)_{6}$} & $\mathrm{P}_{2} \mathrm{O}_{5}$ & $\mathrm{ZrO}_{2}$ & $\mathrm{CaO}$ & $\mathrm{HfO}_{2}$ & \multirow{2}{*}{$\mathrm{ZrO}_{2}-\mathrm{Al}_{2} \mathrm{O}_{3}$} & $\mathrm{Al}_{2} \mathrm{O}_{3}$ & $\mathrm{ZrO}_{2}$ & $\mathrm{Y}_{2} \mathrm{O}_{3}$ & $\mathrm{HfO}_{2}$ \\
\hline & 45.52 & 47.59 & 5.98 & 0.74 & & 59.06 & 37.96 & 2.08 & 0.41 \\
\hline \multirow{2}{*}{ AlN } & AlN & $\mathrm{CaO}$ & $\mathrm{Y}_{2} \mathrm{O}_{3}$ & $\mathrm{Li}_{2} \mathrm{O}$ & \multirow{2}{*}{$\mathrm{MgO}-\mathrm{Al}_{2} \mathrm{O}_{3}$} & $\mathrm{Al}_{2} \mathrm{O}_{3}$ & $\mathrm{MgO}$ & $\mathrm{SO}_{3}$ & $\mathrm{ZrO}_{2}$ \\
\hline & 95.66 & 2.01 & 1.33 & 0.62 & & 51.94 & 46.95 & 0.83 & 0.16 \\
\hline \multirow{2}{*}{$\mathrm{SiC}$} & $\mathrm{SiC}$ & $\mathrm{Al}_{2} \mathrm{O}_{3}$ & $\mathrm{Y}_{2} \mathrm{O}_{3}$ & $\mathrm{CaO}$ & \multirow{2}{*}{$\mathrm{BaFe}_{12} \mathrm{O}_{19}$} & $\mathrm{Fe}_{2} \mathrm{O}_{3}$ & $\mathrm{BaO}$ & $\mathrm{MnO}$ & $\mathrm{SiO}_{2}$ \\
\hline & 83.53 & 10.01 & 5.90 & 0.41 & & 84.62 & 13.98 & 0.73 & 0.41 \\
\hline \multirow{2}{*}{$60^{\#} \mathrm{Al}_{2} \mathrm{O}_{3}$} & $\mathrm{Al}_{2} \mathrm{O}_{3}$ & $\mathrm{SiO}_{2}$ & $\mathrm{ZrO}_{2}$ & $\mathrm{CaO}$ & \multirow{2}{*}{$\left(\mathrm{Ba}_{0.7} \mathrm{~Pb}_{0.3}\right) \mathrm{TiO}_{3}$} & $\mathrm{BaO}$ & $\mathrm{TiO}_{2}$ & $\mathrm{PbO}$ & $\mathrm{SrO}$ \\
\hline & 61.79 & 33.67 & 0.83 & 0.73 & & 47.26 & 32.97 & 16.73 & 1.29 \\
\hline
\end{tabular}


were maintained in the water bath for $10 \mathrm{~s}$. After thermal shock the specimens were cleaned and dried in a drying oven at $100{ }^{\circ} \mathrm{C}$ for $1 \mathrm{~h}$ before the flexural strength was measured. The flexural strength of the specimens was measured in three-point bending test with a span of $30 \mathrm{~mm}$ and a crosshead rate of $0.5 \mathrm{~mm} / \mathrm{min}$ at the ambient temperature in air on a universal testing machine. A single-edge-notched-beam (SENB) test was applied on notched specimen of $4 \mathrm{~mm} \times 5 \mathrm{~mm} \times 50 \mathrm{~mm}$ (notch of $0.2 \mathrm{~mm}$ in width and $2.5 \mathrm{~mm}$ in depth) with $0.05 \mathrm{~mm} / \mathrm{min}$ crosshead speed and $30 \mathrm{~mm}$ span to determine fracture toughness $\left(K_{\mathrm{IC}}\right)$. Mean values and standard deviation for flexural strength were obtained using four specimens for each of the conditions investigated. The presence of thermalshock-induced cracks using a dye penetration into the body of the alumina specimens was examined using an optical microscope (DMLM/P11888500, Leica).

\section{Results and discussion}

Thermal shock behavior of alumina ceramic as a model material was investigated. The specimens were transferred from the heated furnace into the water tank, which took $15 \mathrm{~s}$ in each thermal shock testing, and they were lifted back to the furnace with the same velocity. Figure 1 shows the thermal shock behavior of alumina ceramic as a function of the number of thermal cycles. It can be seen that the flexural strength of all specimens declines abruptly after single thermal shock at three given temperature differences, $\Delta T$, set at $300{ }^{\circ} \mathrm{C}, 600{ }^{\circ} \mathrm{C}$ and $800{ }^{\circ} \mathrm{C}$, respectively. The result, shown in Fig.1, indicates that a great severity of thermal damage arises in the specimens after the first thermal shock. After repeated thermal shock up to the 30th cycle, the retained strength of the specimens does not significantly vary, indicating that no further greater damage occurs in the specimens compared with single thermal shock. Moreover, the strength reduction caused by the quenching test exhibits a similar trend: after a couple of thermal shock cycles, for each given quenching temperature difference, the value of the residual strength of alumina specimens remains almost at a certain level. It is obvious that the higher the temperature difference for thermal shock test, the greater the loss of the strength, indicating the severity of thermal shock damage of the specimens increases as increasing quenching temperature difference.

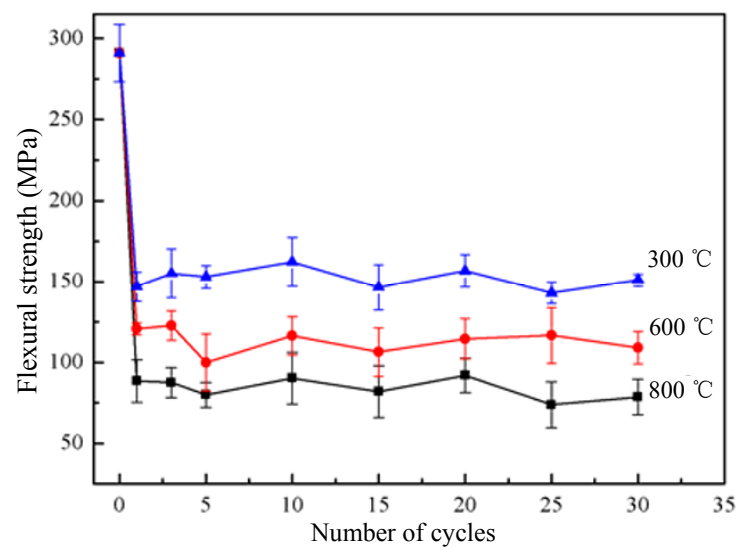

Fig. 1 Thermal shock behavior of alumina ceramic $\left(99^{\#} \mathrm{Al}_{2} \mathrm{O}_{3}\right)$ quenched in water at three different temperature differences as a function of number of cycles.

As the quenching speed increases, i.e., the time taken by transferring specimens into the water tank, $t_{\mathrm{d}}$, reduced to $5 \mathrm{~s}$ from $15 \mathrm{~s}$, the overall trends of the retained strength shown in Fig. 2(a) remain almost the same as Fig. 1, besides that greater loss of flexural strength is observed. It is also worth noting that the quenching temperature difference is another important factor affecting thermal shock behavior of alumina ceramic. When it is lower than $300{ }^{\circ} \mathrm{C}$, the loss of strength is very limited.

Previous studies demonstrated that the tensile stresses yield on the surface of the specimens during cooling, because the surface temperature is lower than the average temperature [12]. The formation of cracks on the surface of the specimens caused by these tensile stresses weakening ceramic materials is shown in Fig. 2(b). Comparing to the as-received specimen, the large cracks occur after the initial thermal shock, which may be the main reason leading to the abrupt decrease in flexural strength. In contrast to initial large cracks, after repeated thermal shock, subsequent crack size is relatively small. According to the statistical theories of fracture [4], the flexural strength of materials after thermal shock is largely governed by the largest cracks, rather than the number of cracks presented on their surfaces. Therefore, the microcracks have a very limited effect on the further decrease in flexural strength of the specimens. From Fig. 2(b), the pattern of cracks on the surface of alumina ceramic reveals a good correlation with the values of retained strength after quenching at the temperature interval of $400{ }^{\circ} \mathrm{C}$. Thus, little changes in strength of alumina ceramic 


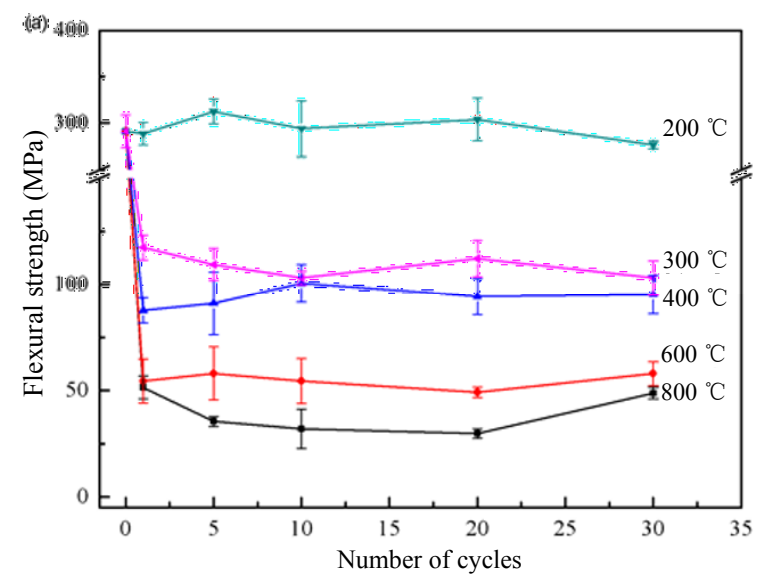

(b)

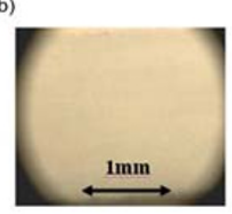

$N=0$

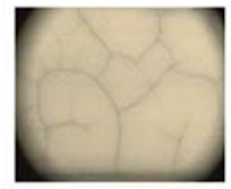

$N=10$

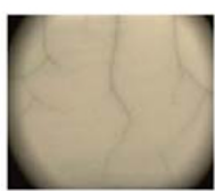

$N=1$

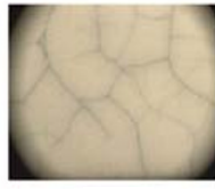

$N=20$

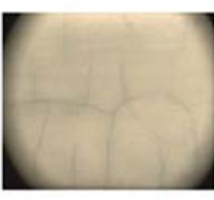

$N=5$

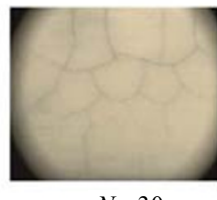

$N=30$
Fig. 2 (a) Changes in strength of alumina ceramic as a function of number of cycles at five different temperature differences ( $t_{\mathrm{d}}$ is $5 \mathrm{~s}$ ); (b) crack patterns in the specimens of alumina ceramic at quenching temperature difference of $400{ }^{\circ} \mathrm{C}(N$ is the number of thermal cycles).

subjected to repeated thermal shock may be attributed to only subcritical microcrack initiation or propagation as increasing number of cycles, because the formed large cracks in the body of alumina ceramic give a necessary space for accommodating thermal stresses as indicated by pronounced R-curve behavior [18]. In principle, it is conceivable that the complete fracture of alumina ceramic is likely to happen when a number of severe flaws have grown on their bodies.

Due to the intrinsic brittleness of ceramic materials, most of them do normally exhibit a particularly sensitivity to environmental conditions [4]. Based on the results obtained on alumina ceramic, we conducted the similar experiments under the standardized conditions on other 19 types of ceramic materials ranging from porcelain, refractory ceramics to advanced ceramics including structural ceramics, electronic ceramics, and low expansion ceramics and ceramic composites were also covered. The result that the flexural strength of most of ceramic materials declines markedly after single thermal shock is shown in Fig. 3. It can also be seen that the strengths of these ceramic materials before and after thermal shock exhibit the similar trend to alumina ceramic, except $\left(\mathrm{Ba}_{0.7} \mathrm{~Pb}_{0.3}\right) \mathrm{TiO}_{3}$ ceramic. Figure 3 reveals that the strength of all the materials decreases initially rapidly, whereas after five thermal shock cycles their flexural strength does not degrade as the number of cycles is increased, reflecting that all materials reach their damage saturation level.

A number of previous works have confirmed that there is a correlation between the degree of thermal shock damage and the change in flexural strength before and after quenching $[13,19,28]$. It is somewhat surprising from the above experimental data that the change degree of each material in flexural strength before and after thermal shock test can reflect its ability in the resistance to thermal shock. A schematic diagram of the strength variation of ceramic materials as a function of number of cycles is illustrated in Fig. 4.
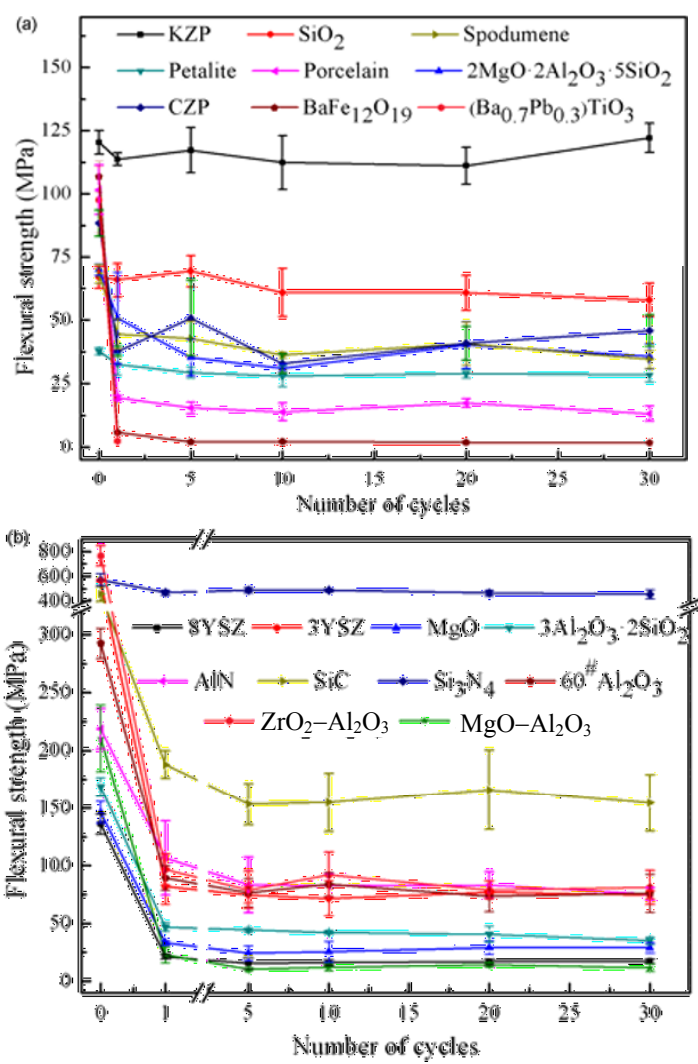

Fig. 3 Retained strength of (a) the materials with relatively low values of original strength and (b) the rest of investigated materials as a function of number of thermal cycles at temperature difference of $600{ }^{\circ} \mathrm{C}$. 3 YSZ: $3 \mathrm{~mol} \%$ yttria stabilized zirconia; 8YSZ: $8 \mathrm{~mol} \%$ yttria stabilized zirconia. $t_{\mathrm{d}}$ is $5 \mathrm{~s}$ in this experiment. 
After repeated cycles, the thermal shock damage after a couple of thermal shock cycles reaches a steady stage, in which the retained strength of ceramics remains approximately a constant value, as shown in Fig. 4. From the above observations, it has been found that the magnitude of change in flexural strength before and after thermal shock can be used as a way of characterization for thermal shock damage of materials. Based on the above results, we propose a normalized method to evaluate thermal shock damage of ceramic materials described as follow.

First, by a standardized test process described above, the as-received strength, $\sigma_{0}$, and the mean retained strength of 5 cycles, 10 cycles, 20 cycles and 30 cycles, $\bar{\sigma}_{\mathrm{r}}$, are obtained. Then, a thermal shock resistance index (TSRI) is introduced by employing the normalized changes in flexural strength after repeated thermal shock to measure a capability of the resistance to weakening or failure when a material is subjected to a rapid change in temperature, and TSRI, $\Gamma$, thus is simply defined as

$$
\Gamma \equiv \frac{\bar{\sigma}_{\mathrm{r}}}{\sigma_{0}} \times 100
$$

where the value of the index $\Gamma$ should fall in the range of 0 to 100 . If the specimens completely fracture during thermal shock test, the value of the index should be zero. However, considering common sense, it may be denoted as $\Gamma<1$ for this case. It is also obvious that the higher value of TSRI, the better the thermal shock resistance. Our further investigations show that the proposed method for evaluation of

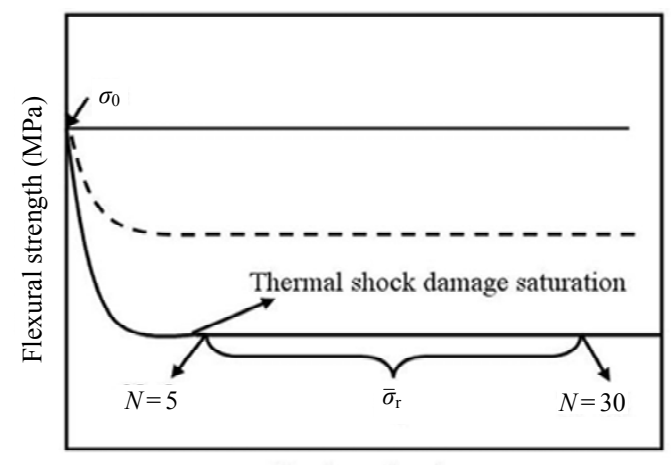

Number of cycles

Fig. 4 Schematic diagram illustrating the extent of thermal shock damage as a function of number of cycles. The solid line and dashed line correspondingly represent the thermal shock behavior of different ceramics; $N$ is the number of thermal cycles. thermal shock resistance is applicable for nearly all kinds of ceramic materials with good comparability and reproducibility.

Part of the properties of 20 types of ceramics measured by quenching in water at the temperature difference of $600{ }^{\circ} \mathrm{C}$ are collected in Table 2. The experimental data presented in Table 2 show that the values of TSRI of the ceramics are all in the range of 0 to 100 . Using this index, it is able to easily rank and compare the capability of thermal shock resistance for different ceramics in a quantitative way. For the examined materials, $\mathrm{KZr}_{2}\left(\mathrm{PO}_{4}\right)_{3}$ ceramic has the highest TSRI, exhibiting its excellent resistance to thermal shock which is closely related to its lower coefficient of thermal expansion. The value of TSRI for classic materials such as alumina, silicon carbide and silicon nitride is 19,34 and 83 , respectively.

The fracture toughness and the corresponding TSRI of several kinds of ceramics are given in Table 3. From Table 2 and Table 3, one may be puzzled about the result that there is no clear correlation between TSRI and fracture toughness of the materials. For example, the values of fracture toughness of $\mathrm{KZr}_{2}\left(\mathrm{PO}_{4}\right)_{3}$ and $\mathrm{CaZr}_{2}\left(\mathrm{PO}_{4}\right)_{6}$ ceramics are very close yet their TSRIs are 96 and 48, respectively. Particularly, the fracture toughness of $3 \mathrm{YSZ}$ is far higher than that of $8 \mathrm{YSZ}$, while their difference in TSRI is very insignificant and both of them are very poor. Though these results more or less betray our intuition, they imply one important aspect, that is, the effect of the fracture toughness on thermal shock resistance of ceramics may be associated with different toughening mechanisms, especially under transient temperature conditions. The toughening mechanism of $3 \mathrm{YSZ}$ may be greatly damaged at temperature as high as $600{ }^{\circ} \mathrm{C}$. On the other hand, the excellent thermal shock resistance of silicon nitride is believed to be ascribed to the high fracture toughness originating for its rod-like grain microstructure which may be not susceptible to temperature change and can be maintained up to elevated temperature. $\left(\mathrm{Ba}_{0.7} \mathrm{~Pb}_{0.3}\right) \mathrm{TiO}_{3}$ ceramic shows the poorest thermal shock resistance among all investigated materials and its TSRI is denoted as 1, the lowest level for thermal shock resistance, due to its complete fracture after the 5 th thermal shock cycle.

The TSRI of 20 types of ceramic materials studied versus their corresponding coefficient of thermal expansion (CTE) is plotted in Fig. 5. The strong dependence of TSRI on CTE is apparent, showing the 
Table 2 List of thermal shock resistance index and part of the properties of the investigated ceramics at quenching temperature difference of $600{ }^{\circ} \mathrm{C}$

\begin{tabular}{|c|c|c|c|c|c|}
\hline Material & $\sigma_{0}(\mathrm{MPa})$ & $\bar{\sigma}_{\mathrm{r}}(\mathrm{MPa})$ & $\Gamma$ & $\alpha\left(10^{-6} \mathrm{~K}^{-1}\right)$ & Apparent porosity (\%) \\
\hline $\mathrm{KZr}_{2}\left(\mathrm{PO}_{4}\right)_{3}$ & $120.38 \pm 4.61$ & $115.34 \pm 4.99$ & 96 & 0.32 & 0.06 \\
\hline Fused $\mathrm{SiO}_{2}$ & $66.8 \pm 4.35$ & $62.15 \pm 4.94$ & 93 & 0.94 & 10 \\
\hline $\mathrm{Si}_{3} \mathrm{~N}_{4}$ & $571.92 \pm 49.08$ & $473.50 \pm 15.71$ & 83 & 3.62 & 1.05 \\
\hline Petalite ceramic & $37.78 \pm 1.42$ & $28.57 \pm 0.56$ & 76 & 3.42 & 8.9 \\
\hline Spodumene ceramic & $68.3 \pm 3.92$ & $38.52 \pm 3.82$ & 56 & 4.13 & 0.3 \\
\hline $2 \mathrm{MgO} \cdot 2 \mathrm{Al}_{2} \mathrm{O}_{3} \cdot 5 \mathrm{SiO}_{2}$ & $69.89 \pm 2.40$ & $35.56 \pm 3.72$ & 51 & 2.07 & 5.3 \\
\hline $\mathrm{CaZr}_{2}\left(\mathrm{PO}_{4}\right)_{6}$ & $88.43 \pm 5.18$ & $42.56 \pm 7.64$ & 48 & 1.93 & 0.27 \\
\hline AlN & $218.85 \pm 17.42$ & $81.09 \pm 3.85$ & 37 & 5.7 & 0.3 \\
\hline $\mathrm{SiC}$ & $457.52 \pm 40.29$ & $157.16 \pm 5.81$ & 34 & 5.24 & 0.17 \\
\hline $60^{\#} \mathrm{Al}_{2} \mathrm{O}_{3}$ & $292.46 \pm 12.88$ & $77.42 \pm 4.44$ & 26 & 8.07 & 0.07 \\
\hline $3 \mathrm{Al}_{2} \mathrm{O}_{3} \cdot 2 \mathrm{SiO}_{2}$ & $168.7 \pm 8.11$ & $41.85 \pm 4.01$ & 25 & 5.6 & 0.8 \\
\hline $99^{\#} \mathrm{Al}_{2} \mathrm{O}_{3}$ & $291 \pm 17.73$ & $54.99 \pm 4.13$ & 19 & 8.29 & 0.08 \\
\hline $\mathrm{MgO}$ & $146.2 \pm 9.42$ & $26.94 \pm 2.39$ & 18 & 13.83 & 1.1 \\
\hline Porcelain & $101.61 \pm 9.81$ & $16.96 \pm 1.86$ & 17 & 6.68 & 0.15 \\
\hline $3 \mathrm{YSZ}$ & $565.7 \pm 9.44$ & $76.06 \pm 2.21$ & 13 & 11.27 & 0.14 \\
\hline $8 Y S Z$ & $135.88 \pm 8.87$ & $16.56 \pm 0.83$ & 12 & 10.36 & 0.1 \\
\hline $\mathrm{ZrO}_{2}-\mathrm{Al}_{2} \mathrm{O}_{3}$ & $765.67 \pm 82.77$ & $82.71 \pm 6.28$ & 11 & 9.12 & 0.09 \\
\hline $\mathrm{MgO}-\mathrm{Al}_{2} \mathrm{O}_{3}$ & $210.48 \pm 28.75$ & $12.15 \pm 1.61$ & 6 & 10.11 & 0.2 \\
\hline $\mathrm{BaFe}_{12} \mathrm{O}_{19}$ & $106.83 \pm 6.09$ & $1.85 \pm 0.61$ & 2 & 12.6 & 1.41 \\
\hline$\left(\mathrm{Ba}_{0.7} \mathrm{~Pb}_{0.3}\right) \mathrm{TiO}_{3}$ & $97.54 \pm 13.15$ & - & 1 & 11.3 & 3.2 \\
\hline
\end{tabular}

Table 3 Fracture toughness and thermal shock resistance index of several ceramics

\begin{tabular}{|c|c|c|c|c|}
\hline & $\mathrm{KZr}_{2}\left(\mathrm{PO}_{4}\right)_{3} \mathrm{CaZr}_{2}\left(\mathrm{PO}_{4}\right)_{6}$ & $\mathrm{Si}_{3} \mathrm{~N}_{4}$ & $3 \mathrm{YSZ}$ & $8 Y S Z$ \\
\hline $\begin{array}{c}K_{\mathrm{IC}} \\
\left(\mathrm{MPa} \cdot \mathrm{m}^{1 / 2}\right)\end{array}$ & $1.64 \pm 0.07 \quad 1.65 \pm 0.10$ & $6.7 \pm 0.36$ & $8.17 \pm 0.27$ & $2.54 \pm 0.22$ \\
\hline$\Gamma$ & 48 & 83 & 13 & 12 \\
\hline
\end{tabular}

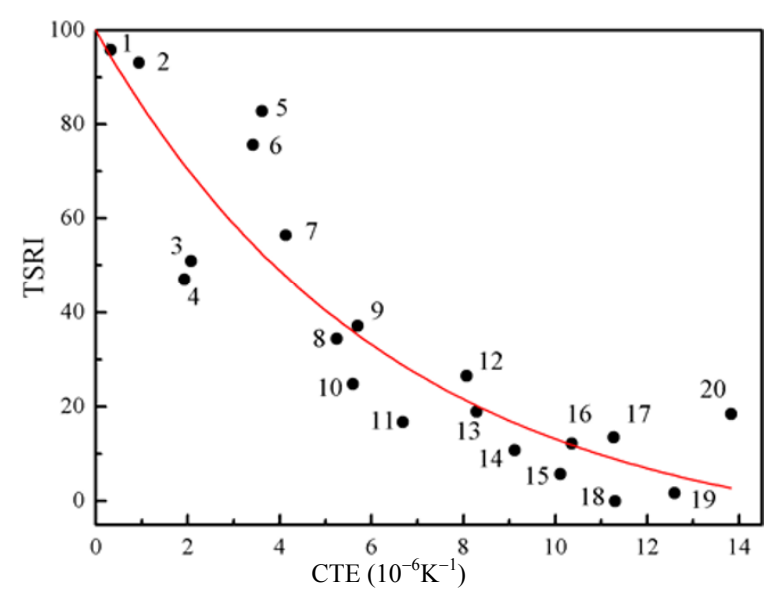

Fig. 5 TSRI of ceramic materials versus corresponding CTE. 1- $\mathrm{KZr}_{2}\left(\mathrm{PO}_{4}\right)_{3}, 2$-fused $\mathrm{SiO}_{2}, 3-2 \mathrm{MgO} \cdot 2 \mathrm{Al}_{2} \mathrm{O}_{3} \cdot 5 \mathrm{SiO}_{2}, \quad 4-\mathrm{CaZr}_{2}\left(\mathrm{PO}_{4}\right)_{6}$, $5-\mathrm{Si}_{3} \mathrm{~N}_{4}, 6$ - petalite ceramic, 7-spodumene ceramic, $8-\mathrm{SiC}, 9-\mathrm{AlN}, 10-3 \mathrm{Al}_{2} \mathrm{O}_{3} \cdot 2 \mathrm{SiO}_{2}$, 11 - porcelain, $12-60^{\#} \quad \mathrm{Al}_{2} \mathrm{O}_{3}, 13-99^{\#} \mathrm{Al}_{2} \mathrm{O}_{3}$, $14-\mathrm{ZrO}_{2}-\mathrm{Al}_{2} \mathrm{O}_{3}, \quad 15-\mathrm{MgO}-\mathrm{Al}_{2} \mathrm{O}_{3}, \quad 16-8 \mathrm{YSZ}$, 17-3YSZ, $18-\left(\mathrm{Ba}_{0.7} \mathrm{~Pb}_{0.3}\right) \mathrm{TiO}_{3}, 19-\mathrm{BaFe}_{12} \mathrm{O}_{19}$, $20-\mathrm{MgO}$. prominent role of CTE in determining the thermal shock susceptibility. The nonlinear relationship between TSRI and CTE probably demonstrates that the factors affecting thermal shock resistance of materials are much more complex. The fitted curve shown in Fig. 5 can be approximated by the following equation:

$$
\Gamma=A \exp (-\alpha / B)+y
$$

where $A=109.70, B=6.42$ and $y=-9.95 ; \Gamma$ is the TSRI; and $\alpha$ is the CTE.

For the fused quartz ceramic $\left(\mathrm{SiO}_{2}\right)$ and the petalite ceramic, with porosity of $\sim 10 \%$ and $\sim 8.9 \%$, respectively, the reason that their actual values of TSRI are higher than the fitted values is possibly ascribed to the pores within the bodies which can decrease the impacts resulting from thermal shock. The higher value of TSRI of the magnesium oxide sample than the fitted is perhaps related to its relatively high thermal conductivity.

\section{Conclusions}

The thermal shock resistance of 20 types of ceramic materials was investigated using water quenching. Thermal shock behavior of all materials studied nearly exhibits the same trend: after repeated thermal shock cycles, up to the 30 th cycle, the retained strength of 
each material remains a certain value. This may be because the cracks of sufficiently large size produced in the bodies of specimens by initial thermal cycles allow that crack propagation takes place quasistatically as increasing number of cycles, which contributes to tolerate the thermal stress and prevent further damage of materials. All the ceramic materials almost reach their damage saturation level at the 5th cycle of thermal shock. A normalized method and the thermal shock resistance index for evaluation of thermal shock resistance for various ceramics are proposed. From the obtained experimental data, it is apparent that the thermal shock resistance index is decreased with the increase of coefficient of thermal expansion. This evaluation method and thermal shock resistance index can be expected to hold for approximately all ceramic materials as a generalized way of quantification, even to give a determining criterion for thermal shock resistance.

\section{Acknowledgements}

This research was supported by a project funded by the Priority Academic Program Development of Jiangsu Higher Education Institutions (PAPD) and by the Program for Changjiang Scholars and Innovative Research Team in University.

Open Access: This article is distributed under the terms of the Creative Commons Attribution License which permits any use, distribution, and reproduction in any medium, provided the original author(s) and the source are credited.

\section{References}

[1] Schneibel JH, Sabol SM, Morrison J, et al. Cyclic thermal shock resistance of several advanced ceramics and ceramic composites. $J$ Am Ceram Soc 1998, 81: 1888-1892.

[2] Katz RN. High-temperature structural ceramics. Science 1980, 208: 841-847.

[3] Schneider GA. Thermal shock criteria for ceramics. Ceram Int 1991, 17: 325-333.

[4] Kingery WD, Bowen HK, Uhlmann DR. Introduction to Ceramics, 2nd ed. New York: John Wiley and Sons, 1976: 817-830.

[5] Wang H, Singh RN. Thermal shock behaviour of ceramics and ceramic composites. Int Mater Rev 1994, 39: 228-244.
[6] Tite MS, Kilikoglou V, Vekinis G. Strength, toughness and thermal shock resistance of ancient ceramics, and their influence of technological choice. Archaeometry 2001, 43: 301-324.

[7] Soboyejo WO, Mercer C, Schymanski J, et al. Investigation of thermal shock in a high-temperature refractory ceramic: A fracture mechanics approach. J Am Ceram Soc 2001, 84: 1309-1314.

[8] Federer JI, Tiegs TN. Analysis of candidate silicon carbide recupurator materials exposed to industrial furnace environments. In Ceramics in Heat Exchangers. Columbus: American Ceramic Society, 1985, 14: 315-334.

[9] Atkinson A, Barnett S, Gorte RJ, et al. Advanced anodes for high temperature fuel cells. Nat Mater 2004, 3: 17-27.

[10] Vedula VR, Green DJ, Hellmann JR, et al. Test methodology for the thermal shock characterization of ceramics. J Mater Sci 1998, 33: 5427-5432.

[11] Colombo P. Ceramic foams: Fabrication, properties and applications. Key Eng Mater 2002, 206-213: 1913-1918.

[12] Bao YW, Wang XH, Zhang HB, et al. Thermal shock behavior of $\mathrm{Ti}_{3} \mathrm{AlC}_{2}$ from between $200{ }^{\circ} \mathrm{C}$ and $1300{ }^{\circ}$ C. J Eur Ceram Soc 2005, 25: 3367-3374.

[13] Gupta TK. Strength degradation and crack propagation in thermal shocked $\mathrm{Al}_{2} \mathrm{O}_{3}$. J Am Ceram Soc 1972, 55: 249-253.

[14] Hasselman DPH. Strength behavior of polycrystalline alumina subjected to thermal shock. J Am Ceram Soc 1970, 53: 490-495.

[15] Kingery WD. Factors affecting thermal stress resistance of ceramic materials. $\mathrm{J} \mathrm{Am} \mathrm{Ceram} \mathrm{Soc}$ 1955, 38: 3-15.

[16] Hasselman DPH. Thermal stress resistance parameters for brittle refractory ceramics: A compendium. Am Ceram Soc Bull 1970, 49: 1033-1037.

[17] Hasselman DPH. Unified theory of thermal shock fracture initiation and crack propagation in brittle ceramics. J Am Ceram Soc 1969, 52: 600-604.

[18] Swain MV. R-curve behavior and thermal shock resistance of ceramics. J Am Ceram Soc 1990, 73: 621-628.

[19] Rendtorff N, Garrido L, Aglietti E. Mullite-zirconia-zircon composites: Properties and thermal shock resistance. Ceram Int 2009, 35: 779-786.

[20] Lu TJ, Fleck NA. The thermal shock resistance of solids. Acta Mater 1998, 46: 4755-4768.

[21] Pettersson P, Johnsson M, Shen Z. Parameters for measuring the thermal shock of ceramic materials 
with an indentation-quench method. $J$ Eur Ceram Soc 2002, 22: 1883-1889.

[22] Maensiri S, Roberts SG. Thermal shock of ground and polished alumina and $\mathrm{Al}_{2} \mathrm{O}_{3} / \mathrm{SiC}$ nanocomposites. J Eur Ceram Soc 2002, 22: 2945-2956.

[23] Andersson T, Rowcliffe DJ. Indentation thermal shock test for ceramics. J Am Ceram Soc 1996, 79: 1509-1514.

[24] Boccaccini DN, Romagnoli M, Kamseu E, et al. Determination of thermal shock resistance in refractory materials by ultrasonic pulse velocity measurement. J Eur Ceram Soc 2007, 27: 1859-1863.
[25] Boccaccini AR, Janczak-Rusch J, Pearce DH, et al. Assessment of damage induced by thermal shock in silicon carbide fiber reinforced borosilicate glass composites. Compos Sci Technol 1998, 59: 105-112.

[26] ASTM International. ASTM C1525-04 Standard test method for determination of thermal shock resistance for advanced ceramics by water quenching. 2013.

[27] British Standards Institution. European Standard EN820-3 Determination of resistance to thermal shock by water quenching. 2004 .

[28] Evans JRG, Stevens R, Tan SR. Thermal shock of $\beta$-alumina with zirconia additions. J Mater Sci 1984, 19: 4068-4076. 